\title{
The Newton's Polynomials Interpolation Based-Error Correction Method for Low-Cost Dive Altitude Sensor in Remotely Operated Underwater Vehicle (ROV)
}

\author{
Gutama Indra Gandha ${ }^{1 *}$, Dedi Nurcipto ${ }^{2}$ \\ ${ }^{1,2}$ Universitas Dian Nuswantoro \\ Jln. Nakula 1 no. 5-11 Semarang, Central java, Indonesia \\ *Corresponding email: gutama.indra@dsn.dinus.ac.id
}

Received 09 January 2019, Revised 16 February 2019, Accepted 26 February 2019

\begin{abstract}
Indonesia is the one of the countries with the largest of sea area. However, the water surveillance categorized as minimum. The human resource and the low level of infrastructure are the causal of the minimum level of water surveillance. The human involvement of water surveillance has many weaknesses, such as weak against the change of the nature condition, limitation in reaching location, weak against water turbidity levels and water pollution. The utilization of ROV (Remotely Operated Underwater Vehicle) could be a solution in water surveillance problem. The development of ROV still not significant in Indonesia. The development costs are also a problem in development of ROV. Many researcher using USBL (Ultra Short Base Line) sensor to sense the depth of the ROV. However, the cost of this sensor is relatively expensive. The usage of low-cost pressure sensor could be a solution to replace the USBL sensor. The low-cost pressure sensor has a significant deviation. The implementation of Newton's polynomials interpolation algorithm has been used to decrease the deviation level of the sensors. The result shows the algorithm has succeeded to decrease the deviation level of the pressure sensor significantly. The MSE value of default sensor was 42956.2, which is significantly worst. The Newton interpolation algorithm has been succeeded to reducing the MSE value to 17.82. The result of this research was expected to reduce the cost of the ROVs development especially for sensors cost.
\end{abstract}

Keywords - ROV, Newton's polynomials interpolation, dive altitude sensor, error correction

Copyright $@ 2019$ JURNAL INFOTEL

All rights reserved.

\section{INTRODUCTION}

Indonesia is the one of the countries with the largest of sea area. The area of the sea is around $66 \%$ of the total area of the country [1]. However, the water surveillance categorized as minimum. The water surveillance including surface water area and deepwater area. The human resource problems and the low level of infrastructure are the causal of the minimum level of water surveillance. Generally, the water surveillance especially deep-water area often involves the human which has many weaknesses. The weaknesses of the human involvement such as weak to the change of the nature conditions, limitations in reaching locations, weak against water turbidity levels and water pollution [2], [3]. The utilization of underwater robot could be a solution to solve the water surveillance problem in Indonesia. One of the types of underwater robot is Remotely Operated Underwater Vehicle (ROV).
ROV is a small-scale submarine vehicle that operated manually from the surface or different place by the operator. ROVs are generally used in deep water exploration and observation such as deep water image acquisition, military operation, rescue operation and subsea pipelines reparation [3]. The development of robot underwater in Indonesia is still not significant [4]. Many aspect must be concerned in the development of ROV such as mechanical and electrical components protection, the robot movement balance, recording of surrounding areas, and the command executions [3], [5]. ROV must have agile and stable movement ability. The maintaining of the dive altitude is a mandatory ability of the ROV [5]. The maintaining of the dive altitude is not easy task. Since the size of the ROV are relatively small. It is highly possible to the disturbance occurrence such as water waves, upper water currents, lower water currents and surrounding objects. In order to 
maintaining of the dive altitudes, the closed loop control system is required.

The closed-loop control system involving sensors as feedback, controller and the plant. The PID controller is the typical type of the controller that used by ROV [6]. Dive altitude sensor is the most critical component in maintaining the dive altitude of the ROVs. Since the dive altitude sensor sends the feedback signal to the controller to calculate the error value. The less error value leads to the more stable of the controlled system. The sensor failure leads to the unstable system. The system failure is the worst effect of the sensor failure [7].

The signal generation of the sensors is not directly generated by physical phenomenon. The generated signal from the sensor could be deviate from the actual condition. The deviation level affects the error level of the sensor. The higher level of deviation leads to the higher level of error [8]. The most researchers utilize the USBL (Ultra Short Base Line) sensor to measure the dive altitude of the ROVs [9], [10], [11]. However, the cost of the USBL sensor is relatively expensive. The alternative option falls to MPX2100DP. The MPX2100DP is piezoresistive pressure sensor. The output voltage of this sensor is linear and proportional to the applied source [12]. It categorized as low-cost sensor. However, this low-cost sensor has significant deviation. The significant deviation leads to significant error. Therefore, the minimization of the error is required. The Newton's polynomial interpolation is the proposed methods that used to minimize the error. The Newton's polynomial interpolation is a powerful algorithm. Many application used this algorithm such as noise removal, error correction, and digital filter [13]-[16]. By using the Newton's polynomial interpolation method, the decrease of the error level is expected. The results of this research have a direct impact to the decrease of the production cost of ROVs vehicles.

\section{RESEARCH METHOD}

The main focus of this research is the error level reduction of the dive altitude sensor by performing the error correction method. Since the usage of low cost piezo resistive sensor as dive altitude sensor is highly possible in leading of significant error during the measurement process. The MPX2100DP is a low cost piezo resistive sensor that used in this research.

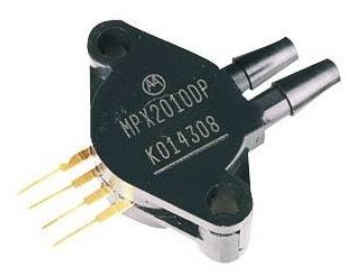

Fig.1. The MPX2100DP Sensor

Many researchers have been working on project with various error correction method. The improvement of the accuracy level of the sensor is the main purpose of the error correction. Liu implemented error correction method to increase the accuracy of the Surface Acoustic Wave (SAW) sensor. The result confirmed that the proposed method able to correct the errors and reduce the standard deviation level [17]. Pop proposed the adaptive algorithm for error correction in temperature measurement. The decrease of the systematic error is an objective of this proposed method. The high frequency noise leads to the error during the measurement which called syst5matic error [18]. The neural network based-error correction method has been proposed by Jiang. The decrease of the error level in pressure sensor measurement is the objective of the proposed method. The results showed the improvement of the sensor performance has been achieved [19]. Zhang has proposed Support Vector Machine (SVM) based-error correction method for infrared methane sensor. This algorithm has been successful to reduce the errors during the measurement that performed by infrared methane sensor. However the support vector machine training is relatively difficult to be performed [20]. Gao proposed a polynomial fitting based-error correction method to reduce the error of the gyro sensor. By using the polynomial fitting method, the errors have been corrected successfully [21]. The similar method of the error correction also performed by Yang. Yang has proposed polynomial fitting based-error correction method for electromagnetic indoor positioning system. This method has been successful to increase the accuracy of the electromagnetic indoor positioning sensor by $1.5 \mathrm{~cm} \mathrm{[22].}$

Polynomial fitting is a powerful method that has ability to perform error correction, outlier removal and automatic defect data fixing. Zhang perform polynomial fitting to remove the outlier in flight data testing. The least square based-polynomial fitting method has been used in this research. This algorithm has been succeeded to remove the outliers under Pauta criterion. It also has ability to repair the defect data's automatically. The flight data testing without outliers has been achieved as the result of the usage of the polynomial fitting [13][23]. Yang has been implemented polynomial fitting to perform error correction in electromagnetic electronic indoor positioning system. The improvement of the accuracy has been successfully achieved [22]. The ability to repair the defect of the data is the effect of the interpolation properties. Since the interpolation properties of this polynomial fitting algorithm then it's called interpolation polynomials algorithm.

Lagrange's polynomials interpolation and Newton's polynomials interpolation are widely used polynomial based-interpolation algorithm in world of computation. Srivastava concludes the Newton's polynomials interpolation has better performance and produce less error percentage than Lagrange's polynomials interpolation. Several function such as trigonometric functions, logarithmic and exponential function have been performed in this research. Every single function involves 10 values with particular interval function. The Lagrange's polynomials interpolation produces higher error percentage than 
Newton's polynomials interpolation [24]. Since those advantages of the Newton's polynomials interpolation algorithm then this algorithm would be implemented in this research.

This research divides into 4 different stages as shown in flowchart in Fig.2.

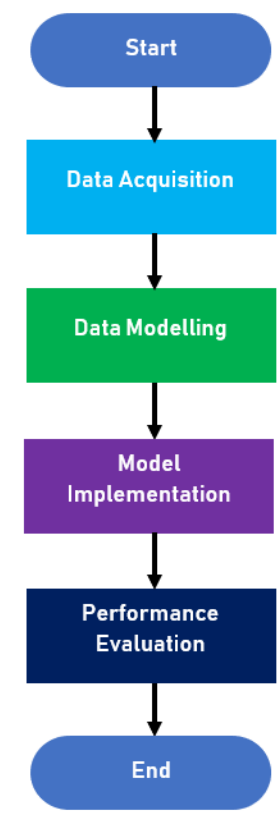

Fig.2. The Research Flow Chart

\section{A. Data acquisition}

The MPX2100DP is categorized as low-cost pressure sensor. This sensor could be utilized as dive altitude sensor for the ROV. However, this sensor has a signification deviation level. The early stage of this research was performing the data acquisition for the sensor at a certain depth range. The depth range is between $0-10$ meters. The result of the acquisition process was a vector values that represent the output of the sensor in a certain range depth. The acquisition process involved MPX2100DP as pressure sensor, microcontroller and serial monitor software.

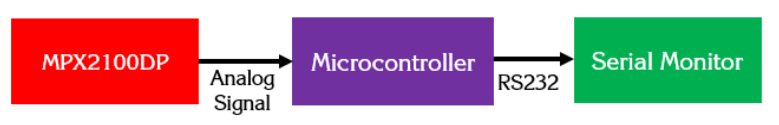

Fig.3. The Hardware Block Diagram For Data Acquisition

Firstly, the analog signal was sent by pressure sensor (MPX2100DP) to analog port of microcontroller. The ADC (Analog to Digital Converter) is required to convert the analog signal into digital signal. After conversion done, the digital output was sent to serial monitor software. The result was a vector value that consist of two elements. First element was the actual depth and the latest was the digital signal value from the sensor. Those elements are important in data modelling stage.

\section{B. Data modeling}

The earliest step for the data modelling stage was to perform an error analysis. The error analysis has been used to observe the deviation level of the sensor measurement. The next step was the data modelling by using Newton's polynomials interpolation algorithm. The result of the data modelling is useful to remove the deviation of the sensor measurement result.

\section{Model implementation}

The data modelling stage was producing the model equation. This model equation was implemented to the microcontroller. The microcontroller processed the analog input then performed the error correction based on the model. The detail of the algorithm implementation stage is shown below:

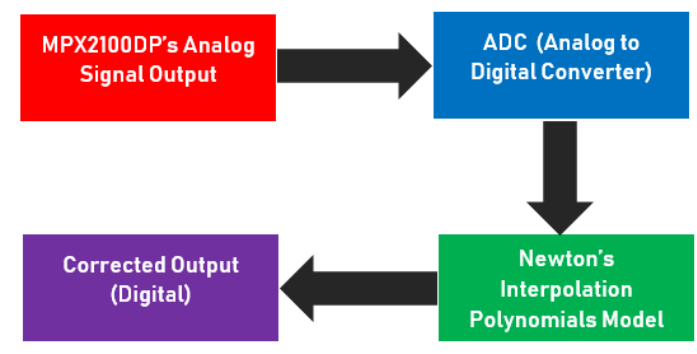

Fig.4. The Implementation Of Newton's Polynomials Interpolation Algorithm

The analog signal from the pressure sensor (MPX2100DP) was measured by ADC. The ADC converts the analog signal form into digital signal form. The 12 bits ADC has been used in this research. The voltage of the ADC's reference voltage was 3 volts. The Newton's polynomials interpolation algorithm performed the error correction and sent the result values in digital form.

\section{Performance evaluation}

The latest stage of this research was performance evaluation. The performance evaluation compared the signal of the sensor before and after using Newton's polynomials interpolation. Due the limitation of the funding, the short-term goal of this research is realization of the low-cost dive altitude sensor. The researchers only compare the production cost of the USBL sensor and our low-cost dive altitude sensor. The performance comparison between USBL sensor and our low-cost dive altitude sensor will be our next research interest.

\section{RESULT}

The data acquisition stage is the most important steps in developing polynomial model. The sensitivity of MPX2100DP sensor is $0.4 \mathrm{mv} / \mathrm{kPa}$. The hydrostatic pressure in water columns for $1 \mathrm{kPa}$ is similar with 10 cm depth.

As shown in the Table 1, the interval for depth measurement is $50 \mathrm{~cm}$. The highest deviation level is occurred at a depth of $1000 \mathrm{~cm}$. It deviates $332.5 \mathrm{~cm}$ from the actual depth. The deviation level of the sensor is proportional to the depth level. The evaluation result is represented in Fig.5. 
Table 1. Data Acquisition Result

\begin{tabular}{crrr}
\hline No. & Depth & $\begin{array}{c}\text { MPX2100DP } \\
\text { Voltage } \\
\text { Output }\end{array}$ & $\begin{array}{c}\text { MPX2100DP } \\
\text { Depth } \\
\text { Measurement }\end{array}$ \\
\cline { 2 - 4 } & \multicolumn{1}{c}{$(\mathbf{c m})$} & \multicolumn{1}{c}{$(\mathbf{m V})$} & \multicolumn{1}{c}{ (cm) } \\
\hline 1 & 0 & 0 & 0 \\
2 & 50 & 0.95 & 23.27 \\
3 & 100 & 1.975 & 49.37 \\
4 & 150 & 3.125 & 78.12 \\
5 & 200 & 4.325 & 108.12 \\
6 & 250 & 5.575 & 139.37 \\
7 & 300 & 6.85 & 171.25 \\
8 & 350 & 8.175 & 204.37 \\
9 & 400 & 9.475 & 236.87 \\
10 & 450 & 10.825 & 270.62 \\
11 & 500 & 12.2 & 305 \\
12 & 550 & 13.575 & 339.37 \\
13 & 600 & 15 & 375 \\
14 & 650 & 16.425 & 410.62 \\
15 & 700 & 17.95 & 448.75 \\
16 & 750 & 19.45 & 486.25 \\
17 & 800 & 20.95 & 523.75 \\
18 & 850 & 22.475 & 561.87 \\
19 & 900 & 24.025 & 600.6 \\
20 & 950 & 38 & 630 \\
21 & 1000 & 40 & 667.5 \\
\hline & & &
\end{tabular}

\section{Depth Measurement Result}

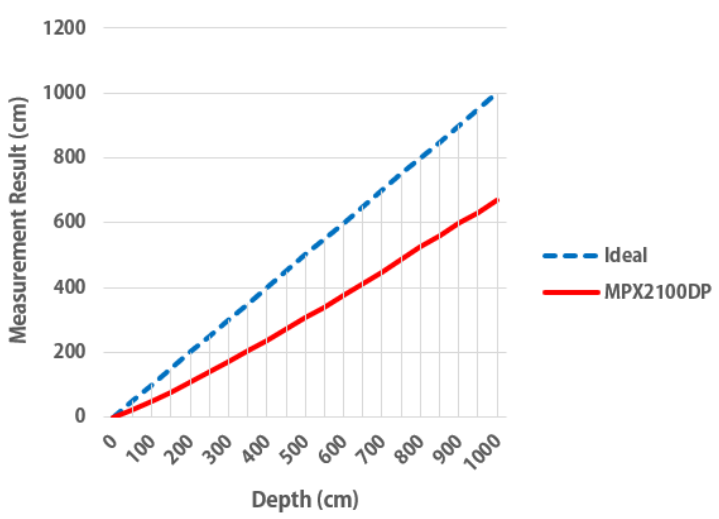

Fig.5. Data Acquisition Result of MPX2100DP Sensor

The result of the MPX2100DP sensor has significant deviation level. Therefore, it is necessary to reduce the deviation of the sensor by using error correction method. Since error level and instability of sensor highly affect the control process. As the worst case, it can lead control process to fail. In the context of ROV's dive altitude control, the implementation of such sensor is highly possible in leading of unstable movement of the ROV's, failure in dive altitude control and catastrophic for the whole ROV's system.

\section{DISCUSSION}

The Newton's polynomials interpolation basederror correction method composed by two steps. The first step is dataset creation. The second step is coefficient calculation.

\section{A. Dataset creation \& coefficient calculation}

This dataset is very important for coefficient calculation. The coefficients were tied with the dataset. A small change of the dataset would affect the coefficient of the model equation. In this research, the dataset was created with only 11 data with $100 \mathrm{~cm}$ interval. Since the data result from the data acquisition was linear.

Table 2. The dataset

\begin{tabular}{|r|r|r|}
\hline $\boldsymbol{i}$ & \multicolumn{1}{|c|}{$\boldsymbol{z}_{\boldsymbol{i}}$} & \multicolumn{1}{c|}{$\boldsymbol{f}\left(\boldsymbol{z}_{\boldsymbol{i}}\right)$} \\
\hline 1 & 0 & 0 \\
\hline 2 & 49.37 & 100 \\
\hline 3 & 108.12 & 200 \\
\hline 4 & 171.25 & 300 \\
\hline 5 & 236.87 & 400 \\
\hline 6 & 305 & 500 \\
\hline 7 & 375 & 600 \\
\hline 8 & 448.75 & 700 \\
\hline 9 & 523.75 & 800 \\
\hline 10 & 600.625 & 900 \\
\hline 11 & 680.625 & 1000 \\
\hline
\end{tabular}

The Newton polynomials interpolation formula gave the polynomials of $n$th degree pasing through the points $\left(z_{i}, f\left(z_{i}\right)\right)$ where $i=0,1, \ldots, n[25]$.

$$
\begin{gathered}
p_{n}([z])=f\left(x_{0}\right)+\pi_{1} f\left[z_{0}, z_{1}\right]+\pi_{2} f\left[z_{0}, z_{1}, z_{2}\right] \\
+\cdots+\pi_{n} f\left[z_{0}, z_{1}, \ldots, z_{n}\right]
\end{gathered}
$$

Where $\pi_{i}=\left(z-z_{o}\right)\left(z-z_{1}\right) \ldots\left(z-z_{i-1}\right)$ and $f\left[z_{0}, z_{1}, \ldots, z_{i}\right]$ is the $i$ th divided difference of $f$ defined by

$$
\begin{gathered}
f\left[z_{k}\right]=f(z) \\
f\left[z_{0}, z_{k}\right]=\frac{f\left[z_{0}\right]-f\left[z_{k}\right]}{z_{0}-z_{k}} \\
f\left[z_{0}, z_{1}, \ldots, z_{i}, z_{k}\right]=\frac{f\left[z_{0}, z_{1}, \ldots, z_{i}\right]-f\left[z_{0}, z_{1}, \ldots, z_{i-1}, z_{k}\right]}{z_{i}-z_{k}}
\end{gathered}
$$

The implementation of the Newton's polynomials interpolation algorithm yielded the model in the form of equation (1). The obtained model has been implemented to the microcontroller in order to fix the error from the MPX2100DP sensor.

\section{B. Performance evaluation}

The comparison of the accuracy level of the sensor has been used to evaluate the performance of the sensor. The performance evaluation compares the accuracy of the MPX2100DP sensor equipped with Newton's interpolation algorithm and standard 
MPX2100DP sensor. The performance evaluation result shown in the Fig. 6 .

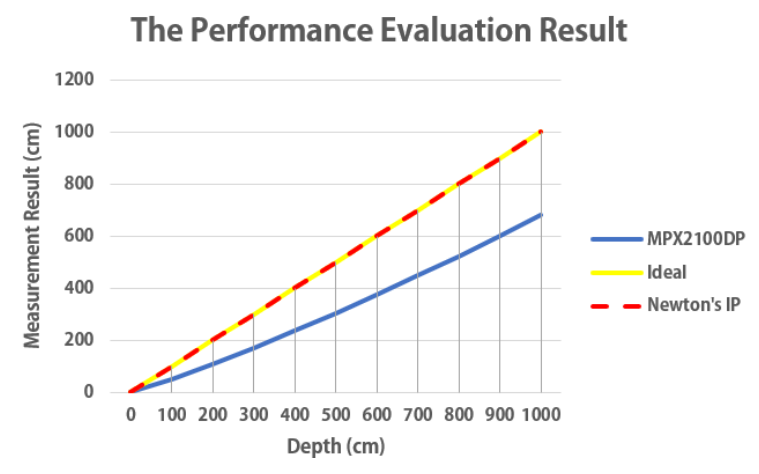

Fig.6. The Performance Evaluation Result

The performance evaluation shows the performance of the sensor equipped with Newton's polynomials interpolation algorithm was better that standard MPX2100DP sensor. The experiment result is shown in the Table 3.

Table 3. The Comparison Betweeen Standard MPX2100DP Sensor And MPX2100DP Sensor Equipped With Newton's Interpolation Algorithm

\begin{tabular}{|c|c|c|c|}
\hline No & Depth & MPX2100DP & $\begin{array}{c}\text { MPX2100DP } \\
\text { with } \\
\text { Newton's } \\
\text { Interpolation }\end{array}$ \\
\hline & (cm) & (cm) & $(\mathrm{cm})$ \\
\hline 1 & 0 & 0 & 0 \\
\hline 2 & 50 & 23.27 & 49.39 \\
\hline 3 & 100 & 49.37 & 100 \\
\hline 4 & 150 & 78.12 & 150.5 \\
\hline 5 & 200 & 108.12 & 200 \\
\hline 6 & 250 & 139.37 & 249.9 \\
\hline 7 & 300 & 171.25 & 300 \\
\hline 8 & 350 & 204.37 & 351 \\
\hline 9 & 400 & 236.87 & 400 \\
\hline 10 & 450 & 270.62 & 449.8 \\
\hline 11 & 500 & 305 & 500 \\
\hline 12 & 550 & 339.37 & 549.5 \\
\hline 13 & 600 & 375 & 600 \\
\hline 14 & 650 & 410.62 & 649 \\
\hline 15 & 700 & 448.75 & 700 \\
\hline 16 & 750 & 486.25 & 749.5 \\
\hline 17 & 800 & 523.75 & 800 \\
\hline 18 & 850 & 561.87 & 851.6 \\
\hline 19 & 900 & 600.6 & 900 \\
\hline 20 & 950 & 630 & 930.8 \\
\hline 21 & 1000 & 680.625 & 1000 \\
\hline
\end{tabular}

The MSE (Mean Squared Error) value is also calculated in this research. The MSE value represents the closeness level to the target value [26]. The MSE formula is shown in the equation (3).

$$
M S E=\frac{1}{n} \sum_{i=1}^{n}\left(\hat{X}_{i}-X_{i}\right)^{2}
$$

The $n$ represents the data quantity, $\hat{X}_{i}$ represents the $n$ number of true values, and $X_{i}$ represents the $n$ number of measurement value. The MSE values for the standard sensor and sensor equipped with Newton's polynomials interpolation algorithm were 42956.2 and 17.82. The result of the MSE values show the sensor equipped with Newton's polynomials interpolation algorithm had better performance than standard sensor. Since it had lower MSE value. The Newton's interpolation algorithm has succeeded to decrease the deviation level of the standard sensor significantly.

In addition to this research, the new sensor characteristic was also presented. Since the sensor utilized new processing algorithm which is Newton polynomials interpolation algorithm then it automatically modified the sensor characteristic. The new sensor characteristic describes the correlation between output voltage of the sensor and depth level. The model of the new sensor characteristic has been obtained by calculating the correlation between voltage output of the sensor and the results of corrected depth measurement as shown in Table 4.

Table 4. Data Acquisition Result

\begin{tabular}{|c|c|c|c|}
\hline No & Depth & $\begin{array}{l}\text { MPX2100DP } \\
\text { Voltage } \\
\text { Output }\end{array}$ & $\begin{array}{c}\text { MPX2100DP } \\
\text { with } \\
\text { Newton's } \\
\text { Interpolation }\end{array}$ \\
\hline & $(\mathrm{cm})$ & $(\mathrm{mV})$ & $(\mathrm{cm})$ \\
\hline 1 & 0 & 0 & 0 \\
\hline 2 & 50 & 0.95 & 49.39 \\
\hline 3 & 100 & 1.975 & 100 \\
\hline 4 & 150 & 3.125 & 150.5 \\
\hline 5 & 200 & 4.325 & 200 \\
\hline 6 & 250 & 5.575 & 249.9 \\
\hline 7 & 300 & 6.85 & 300 \\
\hline 8 & 350 & 8.175 & 351 \\
\hline 9 & 400 & 9.475 & 400 \\
\hline 10 & 450 & 10.825 & 449.8 \\
\hline 11 & 500 & 12.2 & 500 \\
\hline 12 & 550 & 13.575 & 549.5 \\
\hline 13 & 600 & 15 & 600 \\
\hline 14 & 650 & 16.425 & 649 \\
\hline 15 & 700 & 17.95 & 700 \\
\hline 16 & 750 & 19.45 & 749.5 \\
\hline 17 & 800 & 20.95 & 800 \\
\hline 18 & 850 & 22.475 & 851.6 \\
\hline 19 & 900 & 24.025 & 900 \\
\hline
\end{tabular}

The graphic representation of the new sensor characteristic and default sensor characteristic are shown in the Fig.7. 


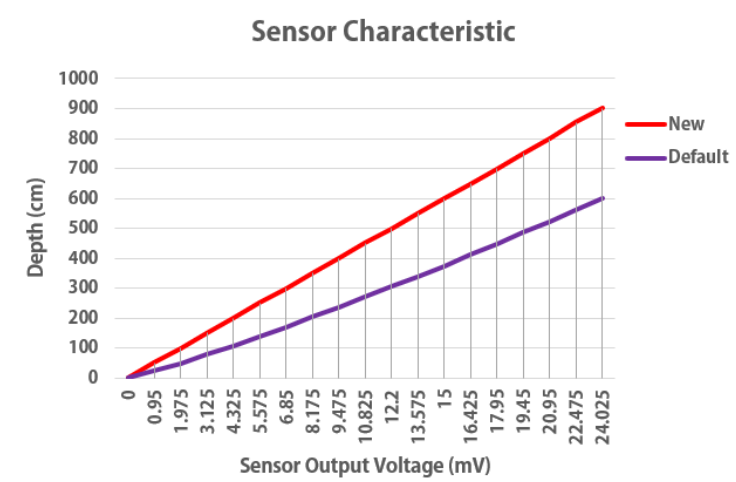

Fig.7. Sensor Characteristics: (a) New Sensor Characteristic (Red Line), (b) Default Sensor Characteristic (Purple Line)

\section{CONCLUSSION}

The high of the development cost is one of a problem the stagnancy of the ROV developments in Indonesia. Sensors are the one of the costly parts in the development of ROV. Many researchers utilize the USBL (Ultra Short Base Line) sensor in the development of ROV. However, the cost of this sensor is relatively expensive. As alternative, the piezo resistive sensor is one of solutions that can be used to replace the USBL sensor. The MPX2100DP is a piezo resistive pressure sensor. The disadvantage of this sensor is in fact that it has worst deviation level. The Newton's polynomials interpolation is the method to decrease the deviation level. The usage of the Newton's polynomials interpolation algorithm has been succeeded to decrease the MSE level to 17.82. The default of the MPX2100DP sensor has MSE value of 42956.2 .

\section{ACKNOWLEDGMENT}

This research has been funded by LPPM (Lembaga Penelitian dan Pengabdian Masyarakat) of Universitas Dian Nuswantoro through University Internal Research Program. The highly gratitude is delivered to Universitas Dian Nuswantoro.

\section{REFERENCES}

[1] Andik Yulianto, "Pengembangan Robot Jelajah Bawah Air Untuk Observasi Terumbu Karang," J. Ilm. Mikrotek, vol. 2, no. 1, pp. 1-9, 2015.

[2] F. Irawan and A. Yulianto, "Perancangan Prototype Robot Observasi Bawah Air dan Kontrol Hovering Menggunakan Metode PID Control," J. Sains dan Inform., vol. 1, no. 1, pp. 63-70, 2015.

[3] Ilham Rizki, "PENGEMBANGAN PROTOTIPE REMOTELY OPERATED ( ROV ): ASPEK MEKANIS,"

http://repository.ipb.ac.id/handle/123456789/5221, 2008.

[4] M. S. Gitakarma, K. U. Ariawan, and N. A. Wigraha, "Alat Bantu Survey Bawah Air menggunakan Amoba, Robot berbasis ROV," J. Sains dan Teknol., vol. 3, no. 2, 2014.

[5] D. W. Santoso, F. Y. Suratman, and R. Nugraha, "KONTROL POSISI KEDALAMAN ROBOT
KAPAL SELAM DENGAN MENGGUNAKAN METODE PID DEPTH POSITION CONTROL OF SUBMARINE ROBOT USING PID METHODE Prodi S1 Teknik Elektro, Fakultas Teknik Elektro , Universitas Telkom Bandung Manual Kontrol Otomatis Pengambilan setpoin," vol. 4, no. 2, pp. 1560-1565, 2017.

[6] A. Z. Abidin, R. Mardiyanto, and D. Purwanto, "Implementation of PID controller for hold altitude control in underwater remotely operated vehicle," Proceeding - 2016 Int. Semin. Intell. Technol. Its Appl. ISITIA 2016 Recent Trends Intell. Comput. Technol. Sustain. Energy, vol. 20, pp. 665-670, 2017.

[7] Aishe Shui, Weimin Chen, Peng Zhang, Shunren Hu, and Xiaowei Huang, "Review of fault diagnosis in control systems," 2009 Chinese Control Decis. Conf., pp. 5324-5329, 2009.

[8] M. L. Fung, M. Z. Q. Chen, and Y. H. Chen, "Sensor Fusion: A Review of Methods and Applications," pp. 3853-3860, 2017.

[9] H. Choi, S. Chung, H. Park, and J. Seo, "Design and control of a convertible ROV," Progr. B. - Ocean. 2012 MTS/IEEE Yeosu Living Ocean Coast - Divers. Resour. Sustain. Act., 2012.

[10] H. T. Choi, J. Choi, Y. Lee, Y. S. Moon, and D. H. Kim, "New concepts for smart ROV to increase efficiency and productivity," 2015 IEEE Underw. Technol. UT 2015, 2015.

[11] S. Choi and O. Easterday, "An Underwater Vehicle Monitoring System and Its Sensors," Exp. Robot. VII, pp. 551-560, 2001.

[12] Freescale, "Freescale Semiconductor Integrated Silicon Pressure Sensor On-Chip Signal Conditioned , Temperature Compensated and Calibrated," Sensors (Peterborough, NH), pp. 2007-2009, 2009.

[13] C.-H. Hsieh, S.-Y. Hung, C.-W. Lan, and P.-C. Huang, "Impulse Noise Removal Based on Grey Polynomial Interpolation," 2010 Seventh Int. Conf. Inf. Technol. New Gener., pp. 327-331, 2010.

[14] C. H. Hsieh, S. Y. Hung, P. C. Huang, and C. W. Lan, "Adaptive polynomial interpolation for noise replacement," 2013 Int. Jt. Conf. Aware. Sci. Technol. Ubi-Media Comput. Can We Realiz. Aware. via UbiMedia, iCAST 2013 UMEDIA 2013, pp. 395-399, 2013.

[15] X. Zeng, P. Yang, and W. Niu, "Design of a filter based on polynomial interpolation and local fit," Proc. - 2009 Int. Forum Inf. Technol. Appl. IFITA 2009, vol. 3, pp. 630-634, 2009.

[16] Q. Cai and L. Song, "The Lagrange Interpolation Polynomial Algorithm Error Analysis," vol. 1, pp. 3719-3722, 2011.

[17] B. Liu, T. Han, and C. Zhang, "Error correction method for passive and wireless resonant SAW temperature sensor," IEEE Sens. J., vol. 15, no. 6, pp. 3608-3614, 2015.

[18] S. Pop, D. Pitica, and I. Ciascai, "Adaptive algorithm for error correction from sensor measurement," 2008 31st Int. Spring Semin. Electron. Technol. Reliab. Life-time Predict. ISSE 2008, pp. 373-378, 2008.

[19] X. Jiang and Y. Bao, "Nonlinear errors correction of pressure sensor based on BP neural network," 2009 Int. Work. Intell. Syst. Appl. ISA 2009, vol. 1, no. 2, pp. 2-5, 2009.

[20] L. Zhang, R. L. Wang, and K. K. Liu, "Study on errors correction of infrared methane sensor based on Support Vector Machines," 2009 2nd Int. Conf. Intell. Comput. 
Technol. Autom. ICICTA 2009, vol. 2, pp. 471-475, 2009.

[21] H. Gao, Z. Wang, and L. Zhang, "Gyro online correctionmethod based on Kalman filter and polynomial fitting," Proc. - 5th Int. Conf. Instrum. Meas. Comput. Commun. Control. IMCCC 2015, pp. 1144-1149, 2016.

[22] X. Yang, X. Meng, T. Jiang, and A. Husnain, "An error correction method based on polynomial fitting to improve the accuracy of the em indoor positioning system," Proc. - 2016 6th Int. Conf. Instrum. Meas. Comput. Commun. Control. IMCCC 2016, no. 3, pp. 932-935, 2016.

[23] L. Zhang, Y. Qin, and J. Zhang, "Study of polynomial curve fitting algorithm for outlier elimination," 2011 Int. Conf. Comput. Sci. Serv. Syst. CSSS 2011 - Proc., pp. 760-762, 2011.
[24] R. Srivastava and P. Srivastava, "Comparison of Lagrange's and Newton's interpolating polynomials," J. Exp. Sci., vol. 3, no. 1, pp. 1-4, 2012.

[25] F. T. Krogh, "Efficient algorithms for polynomial interpolation and numerical differentiation," Math. Comput., vol. 24, no. 109, pp. 185-185, 1970.

[26] E. Holst and P. Thyregod, "A statistical test for the mean squared error," J. Stat. Comput. Simul., vol. 63, no. 4, pp. 321-347, 1999. 